\title{
Induction of prominent $\mathrm{Th} 1$ response in $\mathrm{C} 57 \mathrm{~B} \mathrm{l} / 6$ mice immunized with an E.coli-expressed multi T-cell epitope EgA31 antigen against Echinococcus granulosus
}

\author{
Majid Esmaelizad ${ }^{1,2}$, Gholamreza Ahmadian ${ }^{1}$, Khosrow Aghaiypour $^{2}$, Mehdi Shamsara ${ }^{1}$, Habibellah Paykari ${ }^{2}$ \\ and Majid Tebianian ${ }^{2}$
}

\author{
${ }^{1}$ National Institute of Genetic Engineering and Biotechnology, Shahrak-e-Pajoohesh, Tehran, Iran; \\ ${ }^{2}$ Razi Vaccine and Serum Research Institute, Genomics and Genetic Engineering Department, Karaj, Iran
}

\begin{abstract}
First step in developing an epitope-based vaccine is to predict peptide binding to the major histocompatibility complex (MHC) molecules. We performed computational analysis of unique available EgA31 sequence to locate appropriate antigenic propensity positions. T-cell epitopes with best binding affinity values of $<50 \%$ inhibitory concentration were selected using different available servers (Propred and IEDB). Peptides with $100 \%$ population coverage were selected. A DNA fragment corresponding to the furin linker enriched in Golgi apparatus was inserted sequentially between each epitope sequences in a synthetic DNA in order to cleave the chimeric protein into four separated peptides. Subsequently, the synthetic DNA was cloned into the pGEX4T-1 and pEGFP-N1 vectors and GST-ChEgA31 was expressed in E. coli strain BL21-DE3. The recombinant protein was detected by western blotting using an HRP-conjugated polyclonal anti-GST antibody. Fusion protein purified by affinity chromatography was used to raise antisera in rabbits. Results in agar gel immunodiffusion assay indicated induction of specific antibodies against multiepitope antigen in the tested rabbits. Cytokine assay was carried out in $\mathrm{C} 57 \mathrm{Bl} / 6$ mice and the levels of cytokines were analyzed by sandwich ELISA. Interestingly, production of specific IFN- $\gamma$ was prominently higher in mice immunized with GST-ChEgA31 and pEGFPChEgA31 (650-1300 pg/ml) compared to control groups. No difference was observed in the level of IL-10 and IL-4 in immunized and GST control group. Challenge study with 500 live protoscolices of Echinococcus granulosus on immunized mice demonstrated protectivity level (50-60\%). Based on our results, it appeared that the chimeric protein in the study was able to stimulate T-helper cell-1 (Th1) development and high level of cell mediated immunity in mice.
\end{abstract}

Keywords: cestoda, Taeniidae, paramyosin related protein (EgA31), cytokines, recombinant vaccine, immunization

This article contains supporting information (Table S1) online at http://folia.paru.cas.cz/suppl/2013-60-1-28.pdf

Cystic hydatid disease is considered as one of the major zoonotic parasitic diseases all around the world. This disease is caused by an infection with larval stages of the tapeworm Echinococcus granulosus Batsch, 1786. Adult worms develop in the small intestine of definitive hosts - dogs and other canids (Thompson 1995). Sheep, cattle, goats, camels and pigs serve as intermediate hosts. Ingestion of eggs by natural intermediate hosts or by man, who serves as accidental host, may result in development of larval stages (hydatid cysts).

Cystic hydatid disease may cause economic losses and health problems in human population. Therefore, many attempts were made to prevent transmission of E. granulosus eggs from definitive to intermediate hosts (Lightowlers et al. 1996, Heath and Koolaard 2012). Serological tests and potential vaccines were developed by using purified products of parasite and recombinant antigens (Kittelberger et al. 2002, Dalton et al. 2003).
In a number of previous studies, several recombinant proteins were expressed and analyzed as immunological indicators or vaccine candidates for solving the cross-reactivity problems. One of them, Eg95, belongs to a gene family which conferred a high degree of protection of sheep against challenge infection with eggs of E. granulosus (Lightowlers et al. 1999, Chow et al. 2001). In another study, EgM, EgA31 and EgTrp proteins have been shown to stimulate high protective immunity in dogs (Zhang et al. 2006, Petavy et al. 2008).

Previously, the role of paramyosin in schistosomiasis (Nara et al. 1994), filariasis (Li et al. 1993) and a related paramyosin protein (EgA31) from E. granulosus (Saboulard et al. 2003) were evaluated. EgA31 is a fibrillar protein, which has been regarded as one of the major antigens of E. granulosus (Fu et al. 1999). It has been shown that EgA31 expressed in metacestode stage, particularly in the protoscolices at the subtegumental level (Fu et al. 1999, 
Fraize et al. 2005), could induce cellular and antibody responses in EgA31-immunized dogs (Fu et al. 2000, Saboulard et al. 2003). These observations suggest that EgA31 is highly immunogenic. The aim of the present study was to design and express an epitope vaccine, based on T-cell epitopes of EgA31 protein of E. granulosus and to evaluate its immune response in mice.

\section{MATERIALS AND METHODS}

\section{Prediction of T-cell epitopes}

In order to locate the potential T-cell epitopes, computational analysis of unique EgA31 sequence, consisting of $1836 \mathrm{bp}$ and 600 amino acids residues (GenBank accession number AF067807), was performed. ProPred server (www.imtech.res. in/raghava/propred), was used to predict MHC Class-II binding regions and peptides with the high binding affinity were selected.

\section{Multiepitope cassette construction}

The predicted peptides were assembled with a furin linker (RVKR) between every two epitopes to cleave the chimeric protein into four seperated peptides (Bass et al. 2000, Thomas 2002). Additionally, BamHI, EcoRI and XhoI restriction sites were linked into the 5' and $3^{\prime}$ positions of synthetic DNA to facilitate the cloning process into pGEX4T1 and pEGFP-N1 plasmids (Pasteur Institute, Iran). All rare codons were optimized in multiepitope DNA. Double digested plasmid and synthetic DNA were ligated using T4 DNA ligase enzyme (Fermentas) and transformed into DH5 $\alpha$ competent cells (Pasteur Institute, Iran). Positive colonies were selected and confirmed by PCR amplification.

\section{Expression and affinity purification of fusion protein}

Plasmid pGEX-ChEgA31 was transformed into E. coli BL21-DE3 and protein expression was induced by addition of $0.1 \mathrm{mM}$ IPTG (Fermentas) in 2YT medium at $120 \mathrm{rpm}$, for $5 \mathrm{~h}$ at $30^{\circ} \mathrm{C}$. Protein purification was performed by centrifuging the cell suspension at $5000 \mathrm{rpm}, 10 \mathrm{~min}$ at $4{ }^{\circ} \mathrm{C}$, and resuspending the pellet in binding buffer $(1 \times$ PBS $)$. Sonication was performed six times for 1 min with 1 min interval. PMSF (Sigma Aldrich) was added at the final concentration of $1 \mathrm{mM}$ and then treated with $2 \%$ Triton X-100 (Merck) for an hour at room temperature. The treated samples were pelleted by centrifugation at $15000 \mathrm{rpm}$ for $20 \mathrm{~min}$. Glutathione sepharose 4B was added to the supernatant and incubated on a shaker for an hour at room temperature. The beads were washed twice with $500 \mu$ l binding buffer and GST-ChEgA31 was eluted with $50 \mathrm{mM}$ reduced glutathione (Sigma Aldrich) in Tris- $\mathrm{HCl} \mathrm{pH} 8$.

\section{Western blotting analysis}

Immunoblotting was performed to detect the expression of GST-ChEgA31 by anti-GST HRP conjugated antibody (GE Healthcare Life Science). Briefly, after electrophoresis on $12 \%$ SDS-PAGE for three hours at $100 \mathrm{~V}$, the protein bands were electro-transferred onto a PVDF membrane (Millipore) and blocked for an hour in 1\% BSA (Sigma Aldrich). After washing three times with PBS-T, the membrane was incubated in anti-GST horse radish peroxidase (HRP) conjugated antibody at the dilution of 1:5000 in PBS-T for an hour. Finally, the reaction was developed with $\mathrm{H}_{2} \mathrm{O}_{2}$ and 4-chloro-1-naphtol (4CN) (Sigma Aldrich).

\section{Detection of GFP-ChEgA31 in CHO cells}

Expression of GFP-ChEgA31 protein was detected by a Nikon fluorescence microscope and RT-PCR. Chinese hamster ovary $(\mathrm{CHO})$ cells were transfected with $2 \mu \mathrm{g}$ each of plasmid DNA (pEGFP-ChEgA31 and pEGFP-N1) using Gene Pulser XL (BioRad) according to the manufacturer's instructions. For microscopic analysis, $\mathrm{CHO}$ cells were seeded on $25 \mathrm{~cm}^{2}$ flask (Sigma Aldrich) and grown in RPMI medium (Gibco BRL) supplemented with 10\% fetal bovine serum (Gibco BRL) and $1 \%$ penicillin-streptomycin (Gibco BRL) with $5 \% \mathrm{CO}_{2}$ at $37^{\circ} \mathrm{C}$. Total RNAs from transfected CHO cells with pEGFP-ChEgA31 and pEGFPN1 were prepared by RNA purification Kit (Roche) with DNaseI (RNase-free) to eliminate DNA contamination. One step RT-PCR kit (Roche) was used for RT-PCR.

\section{Animals}

All animal experiments were performed using 7-8 week-old female $\mathrm{C} 57 \mathrm{BL} / 6$, Balb/C mice and 12 week-old female rabbits of $2.5 \mathrm{~kg}$ (provided by the experimental Animal Centre of Razi Vaccine and Serum Research Institute, Iran). Animals were housed in appropriate conventional animal care facilities and handled following international guidelines required for animal experiments. All experimental protocols of this study were conducted in accordance with national and international ethical guidelines (NIH, Guide for the Care and Use of Laboratory Animals) and were approved by the Institutional Committee.

\section{Producing polyclonal antibody}

Trial 1 included chimeric antigen (GST-ChEgA31) and two control groups (GST and PBS+Adj). Three young (12 weeks) female rabbits were injected subcutaneously on day $0,14,28$ with $200 \mu \mathrm{g}$ purified antigens. Freund's complete and incomplete adjuvant were used in the study. Trial 2 included one DNA vaccinated (pEGFP-ChEgA31) and one control DNA (pEGFP$\mathrm{N} 1$ ) groups. Two rabbits were injected with $50 \mu \mathrm{g}$ DNA in $500 \mu \mathrm{l}$ sterile PBS intramuscularly three times with intervals of 14 days. Blood samples from these animals were collected two weeks after last injection and the $\mathrm{ChEgA} 31$ specific antibodies were detected using agar gel immunodiffusion (AGID) assay. Gel diffusion plates consisting of $0.8 \%$ agar and $8.5 \% \mathrm{NaCl}$ were allowed to stand at room temperature for $72 \mathrm{~h}$ before reading.

\section{Immunization of C57BL/6 mice}

Female C57BL/6 mice, 7-8 weeks old were divided in five groups of ten each. Trial 1 included one main group (GST-ChEgA31) and two control groups (Adj, GST). Adj group mice were subcutaneously injected with Freund's adjuvant, GST group were injected with $50 \mu \mathrm{g}$ GST and GST-ChEgA31 group were immunized with $50 \mu \mathrm{g}$ of GST-ChEgA31. All antigens were injected three times subcutaneously by emulsified in Freund's adjuvant with intervals of 14 days. Second trial included two groups of mice (pEGFP-N1, pEGFP-ChEgA31) which were injected with $10 \mu \mathrm{g}$ of DNA in $50 \mu \mathrm{l}$ sterile PBS into the quadriceps muscle of each leg.

\section{Evaluation of IL-4, IL-10 and IFN- $\gamma$ by ELISA}

In cell culture seven groups were considered including two main groups (GST-ChEgA31 and pEGFP-ChEgA31) and five control groups (Adj, GST, Cm(GST), Cm(GSTChEgA31), pEGFP-N1). Two weeks after immunization, spleen cells of C57BL/ 6 mice were cultured in triplicate at $1.5 \times 10^{6}$ cells $/$ well in 24-well plates (Corning, USA) in DMEM medium (Gibco, USA) supplemented with $10 \%$ fetal calf serum (Sigma Aldrich) and penicillin/streptomycin. Spleen cells from different mice groups were in vitro stimulated with the same antigen $(15 \mu \mathrm{g})$ as mentioned in the inoculation protocol. Spleen cells from two groups immunized by DNA cassettes (pEGFP-N1, pEGFP-ChE- 
gA31) were in vitro stimulated with GST-ChEgA31. Supernatants were collected for cytokine analysis $72 \mathrm{~h}$ after stimulation. Production of IL-4, IL-10 and IFN- $\gamma$ were measured by ELISA kit (Quantikine R\&D). Endotoxicity of the purified protein was evaluated by Limulus amoebocyte lysate LAL (Cape Cod, Pyrotell kit) and Rabbit pyrogen test before cell culture.

Experimental infection of immunized mice with live protoscolices

Experiment 1 included Balb/C mice immunization with chimeric antigen (GST-ChEgA31) and two control groups (GST and Adj). Two weeks after the final immunization five mice were challenged with live protoscolices in each group. Viability of protoscolices was assessed by $0.1 \%$ eosin staining. Immunized mice and control groups were injected intraperitoneally with 500 viable protoscolices suspended in RPMI to a final volume of $500 \mu 1 /$ mice.

Experiment 2 included $\mathrm{Balb} / \mathrm{C}$ mice immunization with one DNA vaccine (ChEgA31-GFP) and one control DNA (pEGFPN1) groups (Table 2). Two weeks after the final immunization all mice were challenged with 500 live protoscolices intraperitoneally. Infected mice were killed, on days 90 post-infection. Cyst lesions were counted in immunized and control groups.

\section{Statistical analysis}

Data from cytokine assay were analyzed by $\mathrm{t}$ test, with a $p$ value $<0.05$ considered significant. Software SPSS version 11.5 was used for statistical analyses.

\section{RESULTS}

\section{Antigenic peptide prediction and DNA construction}

Four antigenic peptides were selected using Antigenic Peptides software of Harvard University (Table 1) and putative MHC-II epitopes within the EgA31 protein were also predicted. The selected peptides included $13 \mathrm{MHC}$ II and $30 \mathrm{MHC}$ I epitopes which could identify more than $200 \mathrm{MHC}$ alleles (Table S1). To improve expression and decrease the risk of translational error in E. coli, codon optimization of the synthetic DNA was done due to the presence of a number of rare codons in EgA31 protein. During codon optimization, unwanted restriction sites were avoided, and more abundant codons were selected.

\section{Analysis of chimeric protein}

GST-ChEgA31 encoding a fusion protein with 254 amino acids $(\sim 38 \mathrm{kDa})$ was transformed into $E$. coli strain BL21-DE3. Expression of GST-ChEgA31 was detected by western blotting. The recombinant antigen was purified by glutathione sepharose 4B. Fig. 1 shows the SDSPAGE analysis of the expressed chimeric protein.

A plasmid to express chimeric antigen as GFP fusion protein was constructed and the expression of the ChEgA31-GFP protein in vitro in $\mathrm{CHO}$ cells was confirmed (Fig. 3A). Chinese hamster ovary (CHO) cells with pEGFP-N1 and pEGFP-ChEgA31 constructs were transfected. Fluorescent protein was visualized 72 hours after transfection. The ChEgA31-GFP fusion protein was visible with lower intensity compared to EGFP in CHO cells
Table 1. Prediction of antigenic peptides in EgA31 protein. Four peptides were selected by Antigenic Peptides software of Harvard University in EgA31 protein. Amino acids mark in bold are the first MHCII epitope residues.

\begin{tabular}{lcc}
\hline Peptide-sequence & Length & Position \\
\hline VLLSKIKSLEKTAK & 14 & $87-100$ \\
MRIMALEAENERLRISAAEKQ & 21 & $153-173$ \\
LVGADNSKTTVQSIRNEMRGIQVQIQLLRG & 35 & $242-275$ \\
GYLDL & 19 & $459-488$ \\
LRKASIQKQKLELKDTIIS & &
\end{tabular}

(Fig. 3). This may be due to decreased transfection, transcription or translation efficiency.

\section{Immune assay}

After immunization with pEGFP-ChEgA31, antibodies against full length protein GST-ChEgA31 were detected by AGID. No reactivity was detected for pEGFPChEgA31 stimulated serum against GST.

The three cytokines were assayed by ELISA. To assess the level of vaccine-induced T-cell responses, the immune responses of splenocytes from GST-ChEgA31 or ChEgA31-GFP immunized mice was evaluated. One Th2-related cytokine (IL-4), one Th1-related cytokine (IFN- $\gamma$ ) and one regulatory cytokine (IL-10) were tested.

Splenocytes cultured after vaccination with pEGFPChEgA31 produced high level of IFN- $\gamma$ after stimulation with GST-ChEgA31 antigen. Immunization with GST-ChEgA31 and pEGFP-ChEgA31 induced elevated amount of IFN- $\gamma$ 650-1300 (Fig. 2A). In contrast, there was no difference in the medium alone (Cm-GST and $\mathrm{Cm}-\mathrm{GSTChEgA31)}$, Adj and pEGFP-N1 groups for IFN- $\gamma$ producing cells. Group of immunized mice that received GST alone showed a low level of IFN- $\gamma$ $(<200 \mathrm{pg} / \mathrm{ml})$.

Splenocytes from the Adj immunized group produced low amount of IL-4 $(<7.5 \mathrm{pg} / \mathrm{ml})$ and no significant differences were observed in the level of IL-4 cytokine between Adj and other immunized groups (Fig. 2B). Negligible level of IL-10 (between 10 to $17 \mathrm{pg} / \mathrm{ml}$ ) was observed in all immunized groups (Fig. 2C). No significant differences were observed between Adj and other three GST, GST-ChEgA31 and pEGFP-ChEgA31 main immunized groups.

In all examined groups, medium alone resulted in cytokines values as low as those from non-stimulated splenocytes. Both GST-ChEgA31 and GFP-ChEgA31 induced high level of IFN- $\gamma$ and elicited strong Th1 responses in C57BL/6 mice. In contrast, negligible amount of Th2 cytokines (IL-4 and IL-10) were observed.

Therefore, our data derived from pEGFP-ChEgA31 group are consistent with GST-ChEgA31 inducing IFN- $\gamma$. Cytokine assay evidenced the capacity of ChEgA31 part of GST-ChEgA31 protein and pEGFP-ChEgA31 to induce the expression of a Th1-related cytokine (IFN- $\gamma)$. 
A

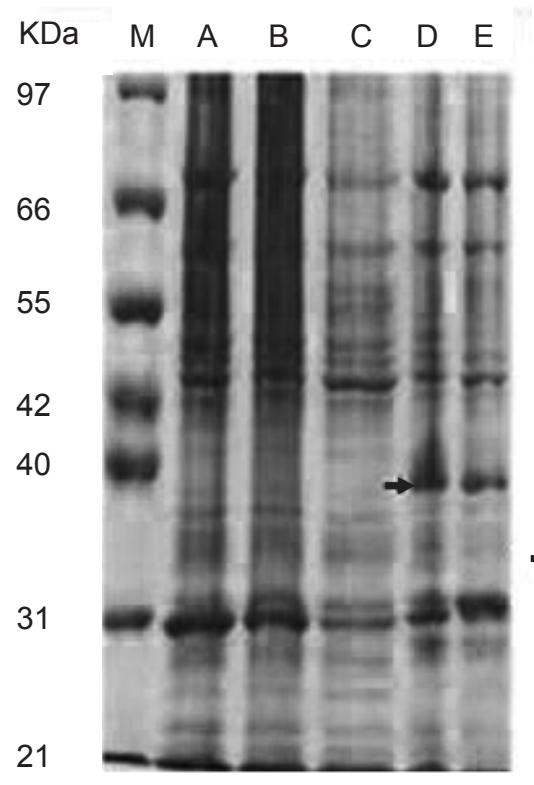

B

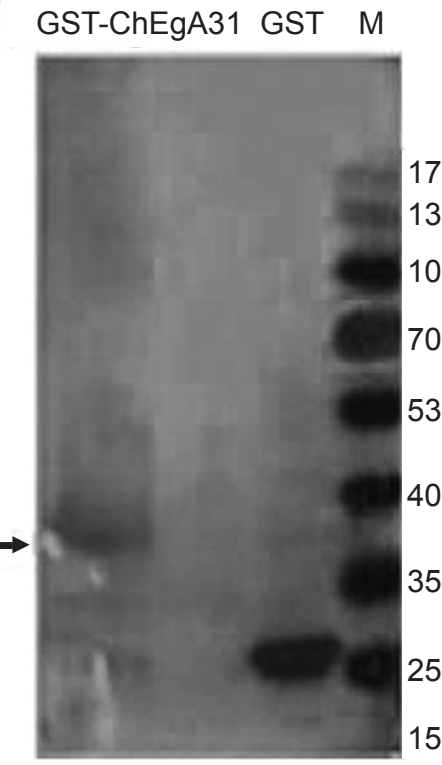

C

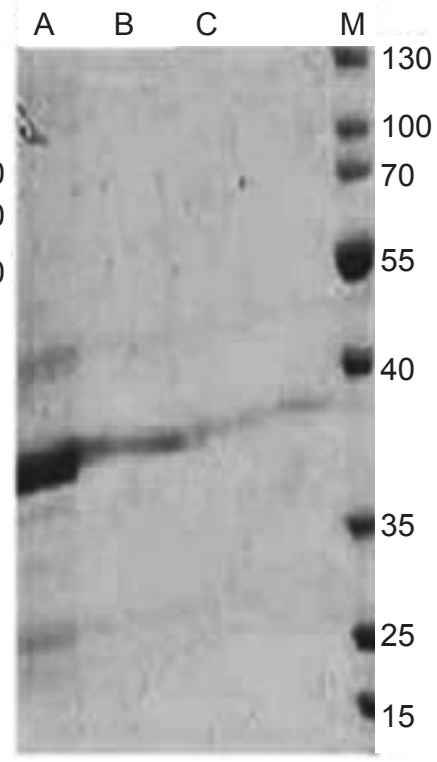

Fig. 1. A - SDS-PAGE analysis of expressed chimeric protein, lane M: mid-range protein molecular weight marker (Promega), lanes A, B: pGEX-ChEgA31 before induction, lane C: chimeric protein after an hour, lane D: chimeric protein after $3 \mathrm{~h}$ induction, lane E: chimeric protein after $16 \mathrm{~h}$ induction; $\mathbf{B}$ - immunoblotting of fusion antigen by anti-GST horse radish peroxidase conjugated antibody, lane GST-ChEgA31: chimeric protein induced by $1 \mathrm{mM}$ IPTG in BL21 cell after $16 \mathrm{~h}$, lane GST: GST protein of PGEX4T1 plasmid induced after $16 \mathrm{~h}$, lane M: prestained protein marker (Fermentas); $\mathbf{C}$ - purification of chimeric protein by affinity glutathione sepharose $4 \mathrm{~B}$, lane A: postsonication pellet of chimeric protein, lane B: purified chimeric protein (first elution), lane C: purified chimeric protein (second elution), lane M: protein size marker (Fermentas).

A

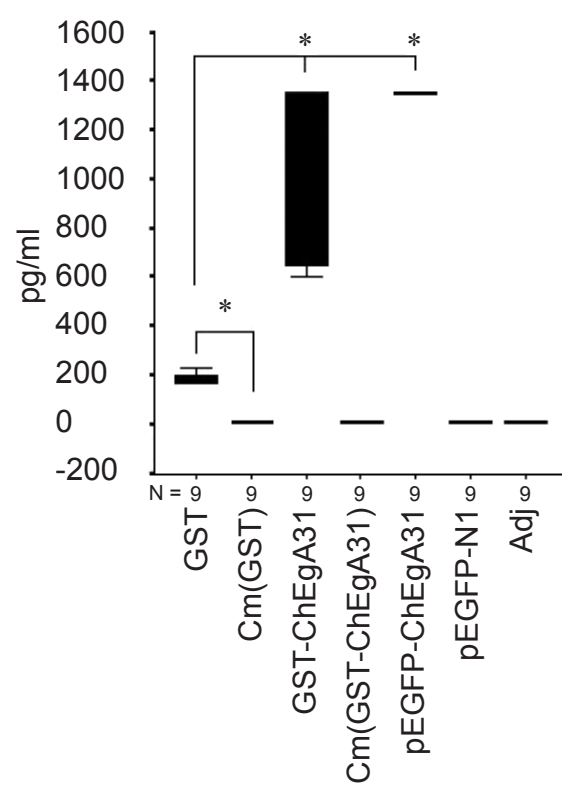

B

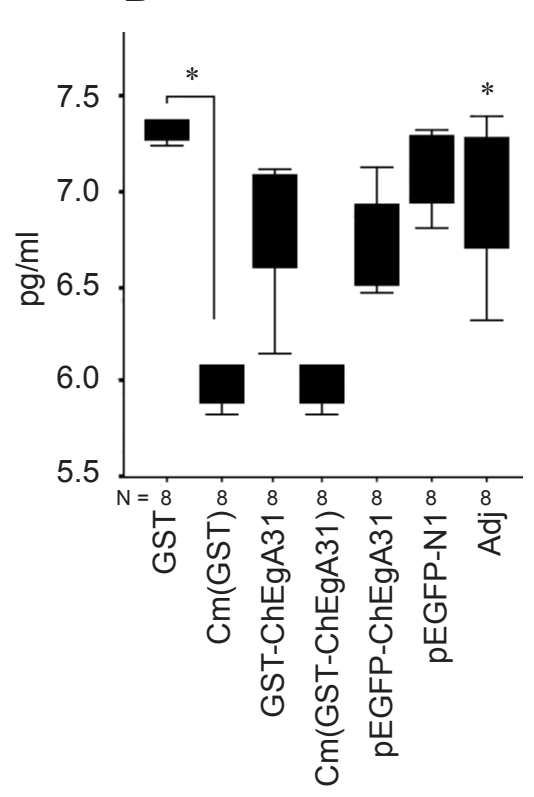

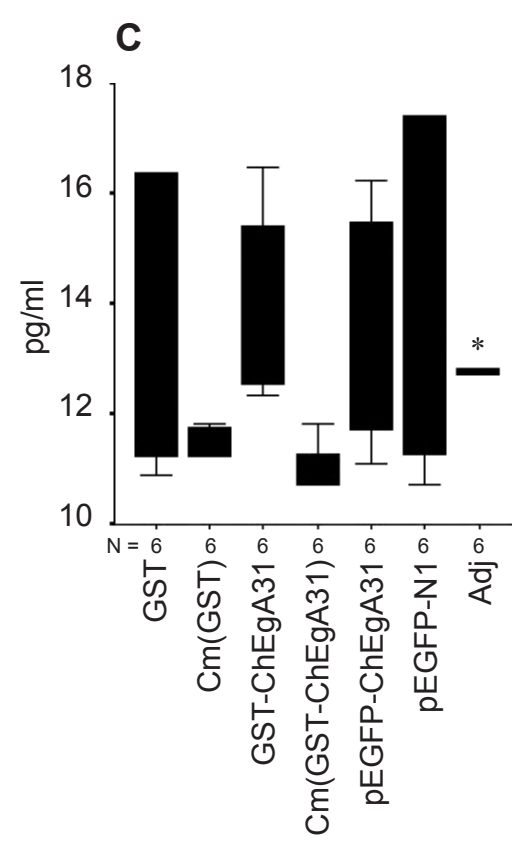

Fig. 2. Cytokine levels in supernatant of cultured spleen cells of immunized mice. Box plots designed by SPSS software for three cytokines levels IL4, IL10 and IFN- $\gamma$ tested by sandwich ELISA kit. A - level of IFN- $\gamma$; B - level of IL-4; C - level of IL-10. For each cytokine seven groups were considered: GST - cells from mice immunized with GST protein, cultured in presence of GST; $\mathrm{Cm}(\mathrm{GST})$ - cells from mice immunized with GST protein, cultured in absence of GST; GST-ChEgA31 - cells from mice immunized with GST-ChEgA31 protein, cultured in presence of GST-ChEgA31; Cm(GST-ChEgA31) - cells from mice immunized with GSTChEgA31 protein, cultured in absence of GST-ChEgA31; pEGFP-ChEgA31 - cells from mice immunized with pEGFP-ChEgA31, cultured in presence of GST-ChEgA31 $*$ p $<0.001$; pEGFP-N1 - cells from mice immunized with pEGFP-N1, cultured in presence of GST-ChEgA31; Adj - cells from mice immunized with adjuvant, cultured in presence of adjuvant. 


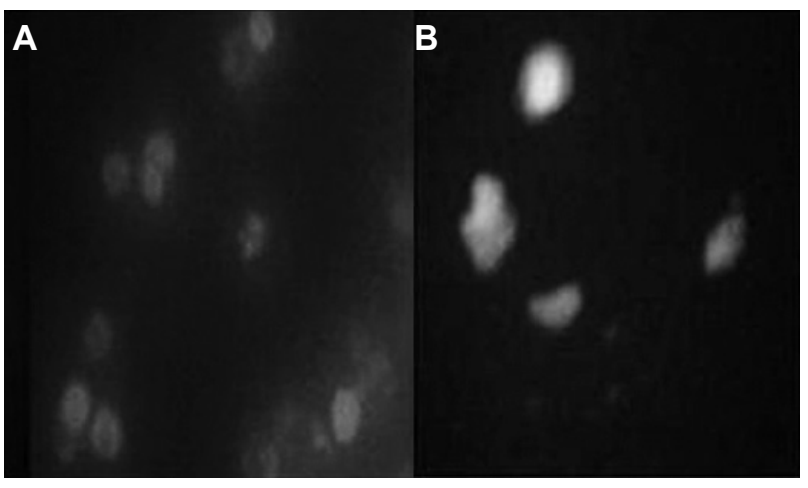

Fig. 3. Expression of $\mathrm{ChEgA} 31-\mathrm{GFP}$ fusion protein in $\mathrm{CHO}$ cells; visualized 72 hours after transfection by fluorescence microscopy; A - CHO cells transfected with pEGFP-ChEgA31; B - CHO cells transfected with pEGFP-N1.

\section{Experimental infection}

Mice in control groups developed cyst lesions of protoscolices infection in the spleen, liver and kidney. Individual lesions exhibited the same morphology including a central parasitic vesicle of approximately $4-6 \mathrm{~mm}$ of diameter.

Experiment 1: Immunization with GST-ChEgA31 resulted in a significant decrease $(\sim 50 \%)$ in the number of hydatid cysts established in mice at three months after infection compared with the number of cysts in control mice group (Table 2). Mice immunized with the GSTChEgA31 protein developed significantly fewer cysts following the challenge infection in comparison with the GST control mice $(\mathrm{P}<0.001$; Table 2$)$.

Experiment 2: Vaccination with pEGFP-ChEgA31 yielded a significant reduction $(\sim 60 \%)$ in the degree of cyst load at three months after infection compared to the pEGFP-N1 control group $(\mathrm{P}<0.001$; Table 2$)$.

\section{DISCUSSION}

All previously described vaccines against Echinococcus granulosus were composed of whole proteins. In the present study we focused on T-cell epitopes, which are exposed to the immune system. We sought to increase Th1 and avoid Th2 immune response in a fusion protein by combining the MHCII epitopes. For this purpose, different epitopes were combined genetically to build up a concatenated chimeric protein. Initially, the antigenic sites of EgA31 protein were predicted. In silico epitope prediction can be used to develop new epitope-based vaccines (Doytchinova and Flower 2003). In the present study it was found that there are four antigenic regions in EgA31 protein. The peptides with the best binding affinities for each allele were investigated and the epitopes with $<50 \mathrm{nM}$ affinity were selected to design a chimeric protein using statistical models for predicting both class I and II alleles (Guan et al. 2003). As there are $90 \%$ correct predictions, MHCPred has currently been the most reliable
Table 2. Vaccination of mice with GST-ChEgA31 and pEGFPChEgA31 against protoscolices. The immunized mice $(n=5$ in every group) were challenged intraperitoneally with 500 live protoscolices and the level of protection was assessed three months post infection.

\begin{tabular}{lccc}
\hline Groups & $\begin{array}{c}\text { No. of le- } \\
\text { sions }\end{array}$ & $\begin{array}{c}\text { \% protection } \\
\text { level }\end{array}$ & P-value \\
\hline Experiment 1 & & & \\
PBS+Adj & 50 & 0 & \\
GST+Adj & 43 & $<14$ & \\
GST-ChEgA31+Adj & 25 & 50 & $\mathrm{P}<0.001$ \\
Experiment 2 & & & \\
pEGFP-N1 & 51 & 0 & \\
pEGFP-ChEgA31 & 20 & $\sim 60$ & $\mathrm{P}<0.001$ \\
\hline
\end{tabular}

predictive tool (Hattotuwagama et al. 2004). In a study conducted by Wiwanikit (2007) bioinformatic tools were successfully used to determine malaria epitopes. According to their report the epitope-based approach is valid and acceptable. In this study, epitopes with $100 \%$ population coverage were selected by MHCPred software based on MHC II alleles (Kolaskar and Tongaonkar 1990).

Song et al. (2009) reported that inclusion body formation and protein insolubility observed during protein expression and purification are considered to represent a limitation in the large-scale purification of proteins. Thus, to avoid the problem of insolubility, the chimeric protein was expressed as a GST fusion protein using pGEX4T1 vector. Solubility was improved by induction of IPTG at low concentration $(0.1 \mathrm{mM})$ and incubation at low temperature $\left(28^{\circ} \mathrm{C}\right)$. Moreover, $2 \%$ Triton $\mathrm{X}-100$ added during purification step could also be one of the factors for achieving improved solubility.

Comparison of GST-ChEgA31 reactivity to sera of rabbits immunized with pEGFP-ChEgA31 DNA cassette showed that the GST-ChEgA31 protein was able to induce antibody responses, which may be due to both parts of fusion protein. The GST-ChEgA31 antigen and pEGFP-ChEgA31 DNA cassette elicited high antibody titre in the immunized rabbit sera compared to those of control groups.

IFN- $\gamma$ is an important immunoregulatory cytokine, which plays key roles in host defence by using anti-proliferative activity (Wheelock 1965, Billiau and Matthys 2009). IFN- $\gamma$ induces the production of cytokines and upregulates the expression of various membrane proteins, including class I and II MHC antigens. IFN- $\gamma$ also influences T-helper cell phenotype development by inhibiting T-helper cell-2 (Th2) differentiation and stimulating Th1 development (Pestka et al. 2004, Schoenborn and Wilson 2007).

However, limited information is available regarding Th1 and Th2 cytokine production in the early phases of a primary E. granulosus infection, although both cytokine levels are low in the early stages of infection, but are raised subsequently (Bauder et al. 1999). Several studies have indicated that Th2-dominated immunity in cystic 
echinococcosis is associated with increased susceptibility to the disease because of the anti-inflammatory action of IL-10. In contrast, Th1 activation is assumed to induce protective immunity (Kakkos et al. 2001, Siracusano et al. 2008, 2012, Sudireddy and Subhash 2009).

In the present study, IFN- $\gamma$ levels were significantly increased in splenocytes of $\mathrm{C} 57 \mathrm{Bl} / 6$ mice immunized with GST-ChEgA31 and pEGFP-ChEgA31 (650$1300 \mathrm{pg} / \mathrm{ml}$ ). However, no significant differences were observed in the levels of Th2 cytokines (IL-10 and IL-4) in the immunized and control groups (GST and pEGFPN1). These results indicate that the GST-ChEgA31 antigen and pEGFP-ChEgA31 DNA cassette are potent inducers of cell-mediated immunity but do not stimulate Th2 development.
The data obtained from experimental infection suggest that $\mathrm{ChEgA} 31$ fusion proteins have effective role in decreased cyst number and peritoneal lesions. These findings are in agreement with the hypothesis that new generation vaccines should be designed based on T-cell epitopes and these candidate vaccines might help induce protective immunity against echinococcosis.

Acknowledgments. The authors wish to thank the National Institute of Genetic Engineering and Biotechnology (NIGEB) of Iran and the Razi Vaccine and Serum Research Institute for support of this project. We would also like to thank Dr. Moharami for providing C57BL/6 mice, Mr. Hejazi and Mrs. Hasheminejad for laboratorial assistance and also to Dr. Mojgani for correcting an early draft of the manuscript.

\section{REFERENCES}

Bass J., Turck C., Rouard A., Steiner D. F. 2000: Furin-mediated processing in the early secretory pathway: sequential cleavage and degradation of misfolded insulin receptors. Proc. Natl. Acad. Sci. USA. 97: 11905-11909.

Billiau A., Matthys P. 2009: Cytokine growth factor. Rev. Apr. 20: 97-113.

Bauder B., Auer H., Schilcher F., Gabler C., Romig T., BilGER B., Aspöck H. 1999: Experimental investigations on the $\mathrm{B}$ and $\mathrm{T}$ cell immune response in primary alveolar echinococcosis. Parasite Immunol. 21: 409-421.

Chow C., Gauci C.G., Cowman A.F., Lightowlers M.W. 2001: A gene family expressing a host-protective antigen of Echinococcus granulosus. Mol. Biochem. Parasitol. 118: 83-88.

Dalton J.P., Brindley P.J., Knox D.P. 2003: Helminth vaccines: from mining genomic information for vaccine targets to systems used for protein expression. Int. J. Parasitol. 33: 621-640.

Doytchinova I., Flower D. 2003: The HLA-A2 supermotif: a QSAR definition. Org. Biomol. Chem. 1: 2648-2654.

Fraize M., Sarciron M.E., Azzouz S., Issaadi N., Bosquet G., Petavy A.F. 2005: Immunogenicity of two Echinococcus granulosus antigens EgA31 and EgTrp in mice. Parasitol. Res. 96: 113-120.

Fu Y., Martinez C., Chalar C. 1999: A new potent antigen from Echinococcus granulosus associated with muscles and tegument. Mol. Biochem. Parasitol. 102: 43-52.

Fu Y., Saint-Andre Marchal I., Marchal T., Bosquet G., Petavy A.F. 2000: Cellular immune response of lymph nodes from dogs following the intradermal injection of a recombinant antigen corresponding to a $66 \mathrm{kDa}$ protein of Echinococcus granulosus. Vet. Immunol. Immunopathol. 74: 195-208.

Guan P., Doytchinova I.A., Zygouri C., Flower D.R. 2003: MHCPred: bringing a quantitative dimension to the online prediction of MHC binding. Appl. Bioinformatics 2: 63-66.

Hattotumagama C.K., Guan P., Doytchinova I.A., Flower D.R. 2004: New horizons in mouse immunoinformatics: reliable in silico prediction of mouse class I histocompatibility major complex peptide binding affinity. Org. Biomol. Chem. 2: 3274-3283.

Heath D.D., Koolaard J. 2012: Serological monitoring of protection of sheep against Echinococcus granulosus induced by the EG95 vaccine. Parasite Immunol. 34: 40-44.
Kakkos S.K., Mouzaki A., Vagianos C.E. 2001: Modifications of the immune system caused by the cestode Echinococcus granulosus: a review. Annals of Gastroenterology. 14: 91-98.

Kittelberger R., Reichel M.P., Jenner J. 2002: Evaluation of three enzyme-linked immunosorbent assays (ELISAs) for the detection of serum antibodies in sheep infected with Echinococcus granulosus. Vet. Parasitol. 110: 57-76.

Kolaskar A.S., Tongaonkar P.C. 1990: A semi-empirical method for prediction of antigenic determinants on protein antigens. FEBS Lett. 276: 172-174.

Li B.W., Chandrashekar R., Weil G.J. 1993: Vaccination with recombinant filarial paramyosin induces partial immunity to Brugia malayi infection in jirds. J. Immunol. 150: 1881-1885.

Lightowlers M.W., Jensen O., Fernandez E., Iriarte J.A., Woollard D.J., Gauci C.G., Jenkins D.J., Heath D.D. 1999: Vaccination trials in Australia and Argentina confirm the effectiveness of the EG95 hydatid vaccine in sheep. Int. J. Parasitol. 29: 531-534.

Lightowlers M.W., Lawrence S.B., Gauci C.G., Young J., Ralston M.J., Maas D., Health D.D. 1996: Vaccination against hydatidosis using a defined recombinant antigen. Parasite Immunol. 18: 457-462.

Nara T., Matsumoto N., Janecharut T., Matsuda H., Yamamoto K., Irimura T., Nakamura K., Aikawa M., Oswald I., SHER A. 1994: Demonstration of the target molecule of a protective IgE antibody in secretory glands of Schistosoma japonicum larvae. Int. Immunol. 6: 963-971.

Pestka S., Krause C.D., Walter M.R. 2004: Interferons, interferon-like cytokines, and their receptors. Immunol. Rev. 202: 8-32.

Petavy A.F., Hormaeche C., Lahmar S., Ouhelli H., Chabalgoity A., Marchal T., Azzouz S., Schreiber F., Alvite G., Sarciron M.E., Maskell D., Esteves A., Bosquet G. 2008: An oral recombinant vaccine in dogs against Echinococcus granulosus, the causative agent of human hydatid disease: a pilot study. PLoS Negl. Trop. Dis. 2: 125.

Saboulard D., Lahmar S., Petavy A.F., Bosquet G. 2003: The Echinococcus granulosus antigen EgA31: localization during development and immunogenic properties. Parasite Immunol. 25: 489-501. 
Schoenborn J.R., Wilson C.B. 2007: Regulation of interferongamma during innate and adaptive immune responses. Adv. Immunol. 96: 41-101.

Siracusano A., Delunardo F., Teggi A., Ortona E. 2012: Hostparasite relationship in cystic echinococcosis: an evolving story. Clin. Dev. Immunol.: 639362.

Siracusano A., Riganò R., Ortona E., Profumo E., Margutti P., Buttari B., Delunardo F., Teggi A. 2008: Immunomodulatory mechanisms during Echinococcus granulosus infection. Exp. Parasitol. 119: 483-489.

Song H.S., Lee S.H., Oh E.H., Park T.H. 2009: Expression, solubilization and purification of a human olfactory receptor from Escherichia coli. Curr. Microbiol. 59: 309-314.

Sudireddy C., Subhash C.P. 2009: Serum antibody \& Th2 cytokine profiles in patients with cystic echinococcosis. Ind. J. Med. Res. 130: 731-735.
Thompson R.C.A. 1995: Biology and systematics of Echinococcus. In: R.C.A. Thompson and A.J. Lymbery (Eds.), Echinococcus and Hydatid Disease. CAB International, Wallingford.

Thомаs G. 2002: Furin at the cutting edge: from protein traffic to embryogenesis and disease. Nat. Rev. Mol. Cell. Biol. 3: 753-766.

Wheelock E.F. 1965: Interferon-like virus induced in human leukocytes by phytohemagglutinin. Science 149: 310-311.

WiWANIKIT V. 2007: A preliminary report on predicted epitopes of malarial VAR2CSA by bioinformatics method: a clue for further vaccine development. Centr. Eur. J. Immunol. 32: 169-171.

Zhang W., Zhang Z., Shi B., Li J., You H., Tulson G., Dang X., Song Y., Yimiti T., Wang J., Jones M.K., McManus D.P. 2006: Vaccination of dogs against Echinococcus granulosus, the cause of cystic hydatid disease in humans. J. Infect. Dis. 194: $966-974$.

Accepted 26 September 2012 